\title{
Evaluating Multimedia Exposure on Pass Rates of Private Pilots
}

\author{
Peter M. Dittmer \\ Vaughn College of Aeronautics and Technology
}

\begin{abstract}
The purpose of this study was threefold: first, to evaluate the effect of multimedia presentations versus traditional presentations on the academic achievement of college students enrolled in an introduction to aviation class at a historically Black institution located in a southern state; second, to investigate the influence of gender, experience, and class attendance on the academic achievement of aviation students; and finally, to assess the influence of type presentation (multimedia and traditional) on the course satisfaction scores of aviation students. A posttest-only control-group design was employed in this investigation to collect and analyze the data. Twenty-five students (16 exposed to traditional presentations and 9 exposed to multimedia presentations) were selected to participate in this empirical study. Two instruments, entitled Questionnaire on the Effect of Traditional Method Presentations and Questionnaire on the Effect of Multimedia Presentations, were used to gather the data. The results of the data analysis showed no significant difference between the written examination scores of aviation students by type of presentation. An interesting finding of the study was the significant influence of the variables gender and class attendance on the academic performance of aviation students. Female students did significantly better on the written examination than their male counterparts. In addition, students who missed fewer days did better on examinations than those who missed more days.
\end{abstract}

\section{INTRODUCTION}

In recent years, a number of learning systems based on interactive instructional videos have been developed (Marinelli \& Stevens, 1998; Pimentel, Ishiguro, Abowd, Kerimbaev, \& Guzdial, 2001). Kearney, Treagust, Yeo, and Zadnick (2001) developed a system to use interactive digital video clips to present 16 realworld demonstrations to physics students in order to elicit their preinstructional concepts. Feedback from student questionnaires indicated that students perceived meaningful interactions taking place during their engagement with the program.

In the past few years, video technology has been adopted widely to enhance the learners' perceptions of live interaction with virtual instructors through the Internet. These systems vary in the way the multimedia content is organized and presented. Specifically, those systems can be classified as either synchronous or asynchronous (Offir, Lev, \& Bezalel, 2008). Harman and Dorman (1998) developed a system that integrated desktop video conferencing and an audio-graphic methodology to establish an effective virtual face-to-face learning environment for mathematics. The system enabled visual contact between lecturers and students. Electronic boards, application software, and videotapes also were utilized, and PowerPoint slides were included to convey text, equation mode, and graphics on electronic whiteboards.

At the time of this study, little research had been conducted into the successful multimedia delivery methods for students taking the private pilot written examination. Flight instructors have been given multimedia tapes to supplement the flight school's curriculum to help students pass written examinations. FBO's as well as collegiate aviation programs have limited resources and relied on adjunct faculty members to teach a variety of classes. Some adjuncts had more teaching experience than others, which varied the time and emphasis spent on certain areas of the curriculum. This lack of expertise became a problem when the students were tested at the end of the semester, leaving some students unprepared or inadequately prepared for examinations given by the Federal Aviation Administration (FAA). The exam, which comes from a database that selects questions randomly, is difficult to prepare for. By design, the curriculum for the introduction to aviation class incorporates concepts for the student to grasp basic aeronautics terminology. After receiving a 
multimedia presentation at the end of the semester, each student will have the knowledge to pass the private pilot examination.

\section{RESEARCH METHODOLOGY}

\section{Purpose of the Study}

One purpose of the study was to evaluate the pass rates of students enrolled in an introduction to aviation class at a historically Black institution in a southern state, taking the private pilot written test after being exposed to multimedia instruction. This study also sought a better way to teach student pilots to retain information and increase passing rates on the private pilot written examination. Study subjects were enrolled in a university's aviation program. Each participant for this study had completed Introduction to Aviation (AWS 101), but had not taken the private pilot written examination administered by the FAA.

\section{Research Design}

This research used a posttest-only control group design, with participants assigned randomly to the experimental and control groups. The independent variables were students receiving the treatment, and the dependent variable was the pass rate on the private pilot written examination. Both the experimental and control groups were given the posttest; the experimental group was given the treatment, but the control group was not given the treatment. This design was chosen because a pretest might have an effect on the experimental treatment (Gall, Gall, \& Borg, 2003). If the experimental group performed better on the posttest, this result could not be attributed to pretesting because both groups had the same pretesting experience.

\section{Procedures}

Once the semester started, students preparing for the FAA Private Pilot Written Exam were recruited to participate in this study. A purposeful and convenient sample group was asked to participate in a scheduled prep course designed to help students pass the FAA Private Pilot Written Exam. The software for the multimedia instruction was supplied by Aviation Supplies and Academics, Inc. The control group received a traditional curriculum delivered by an instructor in a classroom setting. The experimental group received a curriculum delivered in a multimedia format. Then, each participant took the FAA Private Pilot Written Exam.

A posttest was administered after the multimedia-enhanced instruction was given to the experimental group. Both tests were timed and taken on computers, using the course management system in Class Climate, a computer software system that an instructor can use to manage student course work and administer examinations on a computer network. All students were experienced with the testing format and were informed that test questions would not count toward their grade in the course. Test questions on the posttests were identical.

The test questions were derived from a pool of questions from the FAA written test bank of questions pertaining to the private pilot written tests for airplanes. Then, the data yielded by a factorial design was analyzed by doing a $t$ test to compare the difference between the posttest mean scores of the experimental and the control groups. The reliability of the instrument used in this study was measured using a Cronbach alpha measurement. Because a pretest was not administered, a test or retest for reliability was not used.

In order to demonstrate content validity, test items were verified as matching content presented both in multimedia-enhanced instruction and traditional textbook instruction. Furthermore, the investigative questionnaires were validated by a group of authorities in research and statistics. The instruments had alpha coefficients of .84 and .86 , respectively.

\section{RESULTS OF THE STUDY}

The sample population for this introductory aviation class was composed of 25 students enrolled in the introductory aviation class. An instrument entitled "Questionnaire on the Effect of Multimedia Presentation” was used to collect the data. The data analysis was accomplished in two phases. The first phase dealt with the demographic characteristics of the respondents in this empirical investigation. The second phase addressed the six major research questions 
formulated for the study. The $t$ test of independent samples, Chi-square test, one-way analysis of variance, and the Scheffé Multiple Comparison Test were used to treat the data.

Twenty-five aviation students participated in this study. All were enrolled at the participating university as airway science majors. These were described by type of presentation, gender, and age. Type of presentation was categorized into two subgroups for this investigation. Sixteen students were enrolled in the traditional presentation class and 9 students were enrolled in the multimedia classes. Twenty-two students identified themselves as male and 3 students identified themselves as female. Four distinct age groups were reported in the study: 19 years of age or younger, 20-25 years old, 26-30 years old, and 31 years old or older (see Table 1 ).

Question 1 was "What are the effects of multimedia presentations versus traditional presentations on private pilot written exam results?" An independent samples $t$ test was completed to examine the differences in private pilot written examination scores between students who received multimedia presentations and those who received traditional presentations. As shown in Table 2, the mean examination score for the multimedia group of students was $3.11(S D=1.69)$ and the mean examination score for the traditional group of students was $2.25(S D=1.18)$. No statistically significant differences were found between the examination scores of the students receiving multimedia presentations and those receiving traditional presentations.

Question 2 was "What are the effects on the pass rate of those students receiving multimedia presentations and those who did not receive multimedia presentations on the pilot written examination?" The independent samples $t$ test was computed on the differences between AWS 101 scores of students who received multimedia presentations and those who received traditional presentations. As shown in Table 3, the mean AWS 101 score for the multimedia groups of students was $3.63(S D=.72)$. No statistically significant differences were found between the mean AWS 101 scores of students who received multimedia presentations and those receiving traditional presentations at the .05 level.
Question 3 was "Does the gender of multimedia and traditional students impact their pass rates?” Reported in Table 4 are the $t$-test results pertaining to the differences between the AWS 101 scores of male and female students. The mean AWS 101 score for male students was $3.50(S D=.74)$ and the mean AWS 101 score for female students was $4.00(S D=.01)$. A statistically significant difference was found between the mean AWS 101 scores of male and female students at the .01 level. Thus, it can be concluded that female students had significantly higher AWS scores than their male counterparts.

Question 4 was "Do experience factors such as accumulated flight hours affect pass rates of those students receiving multimedia presentations on the private pilot written exam?” In order to examine the experience factors of students, two items on the questionnaire were used. Item 8 on the multimedia survey and Item 28 on the traditional survey asked the students if having flight time helped in preparing for the FAA Private Flight Examination (see Table 5). When the Chi-square test of independence was computed between this experience factor and the pass rate of students, a statistically significant difference was found between the two variables at the .05 level $\left(X^{2}=6.836 ; d f=2 ; p=.033\right)$. The students who agreed that having flight time was helpful were significantly more likely to pass the private pilot examination.

Further, Item 9 on both surveys asked the students if having soloed before taking the FAA Private Pilot Examination helped in their preparation. When the chi-square test was calculated between this experience factor and the pass rates of students, no significant difference was found at the .05 level in the number of students who passed or failed the examination based on whether they agreed, disagreed, or had no opinion about whether having soloed helped $\left(X^{2}=1.495 ; d f=2 ; p>.05\right)$.

Question 5 was "What are the effects of multimedia and traditional presentations on course satisfaction?” The variable course satisfaction was measured by Item 7 on the multimedia survey and Item 27 on the traditional survey. These items asked the participants, "Are you satisfied using multimedia or traditional presentations for the FAA Private Pilot Examination?" Shown in Table 7 are the results 
relative to the influence of type of presentation on course satisfaction as perceived by the students. No statistically significant difference was found at the .05 level between course satisfaction of students who received multimedia versus traditional presentations $\left(X^{2}=5.855 ; d f=\right.$ $2 ; p<.05)$.

Question 6 was "Do students who attend the introduction to aviation class on a regular basis score higher after multimedia presentations than those who do not?" The one-way analysis of variance results regarding the regular basis scores of students receiving multimedia and traditional presentations by class attendance are presented in Table 8. A statistically significant difference was found between the regular basic scores of the four attendance groups of students $(f=8.136 ; d f=4 / 20 ; p<.001)$ at the .001 level. Further data analysis using the Scheffé test as a follow-up revealed that students who missed 2-3 days of classes had a significantly higher score than those who missed 4 or more days of classes (see Table 9). No other mean differences were observed.

\section{SUMMARY OF RESEARCH QUESTIONS}

Six research questions were formulated and tested for differences between the variables. Of the six research questions, Questions 3, 4, and 6 were found to be significant (see Table 10).

The results from Question 3 revealed that female students had significantly higher classroom performance scores than their male counterparts. Research Question 4 data revealed that students who agreed with the benefits of having flight time were significantly more likely to pass the private pilot examination. Finally, according to Question 6, aviation students who missed the fewest days from class outperformed those who missed more days.

\section{ANALYSIS}

The posttest-only control group design was employed in this investigation to collect and analyze the data. Twenty-five students (16 exposed to traditional presentations and 9 exposed to multimedia presentations) were selected to participate in this empirical study. Two instruments entitled Questionnaire on the
Effect of Traditional Method Presentations and Questionnaire on the Effect of Multimedia Presentations were used to gather the data. The investigative questionnaires were validated by a group of authorities in research and statistics. The instruments had alpha coefficients of .84 and .86, respectively.

Moreover, the data were tested through the application of the $t$ test of independent samples, Chi square test of independence, one-way analysis of variance, and the Scheffé multiple comparison test.

\section{Findings}

Based on the results of this study, the following findings were observed:

1. The written examination scores of aviation students were not affected significantly by type of presentation.

2. Type of presentation (multimedia and traditional) did not produce a significant effect on the classroom performance scores of aviation students.

3. Male and female aviation students performed differently on the classroom performance scores.

4. The performance factor of having flight time did not produce a significant impact on the private pilot examination scores of aviation students.

5. The experience factor of having soloed before taking the FAA Private Pilot Examination did not produce a significant influence on the examination scores of aviation students.

6. Type of presentation did not produce a significant influence on the course satisfaction of students.

7. Class attendance did produce a significant effect on the classroom performance scores of aviation students receiving multimedia and traditional presentation.

One of the most interesting findings of this study pertained to the influence the type of presentation had on the academic performance of aviation students. To be sure, aviation students who received multimedia presentations and those who received traditional presentations had similar private pilot written examination 
scores. These findings were not consistent with those of Carville and Mitchell (2000), Clariana (2003), Hayes and Robinson (2000), Williams and Dwyer (1996), and Zhang (1995). All of the above researchers found that some form of multimedia presentation was superior to traditional presentation with regard to improving the academic performance of students.

However, the present findings were consistent with those of Dillon and Gabbard (1999), Mbarika et al. (2001), VarHagen and Zumbo (1990), and Morales et al. (2001). The aforementioned researchers found that students who received a traditional presentation tended to perform as well as their peers who received a multimedia presentation.

A plausible explanation for the prevailing findings with regard to the impact of the type of presentation on the academic performance of aviation students might be that the amount of time exposed to multimedia materials and the type of multimedia used could have hindered the quality of instruction received by the multimedia students. Also, the attitudes of aviation students toward multimedia presentations as well as toward traditional presentations could have been a factor in the performance of these students on the private pilot written examination.

It is interesting to note here that the traditional students had a higher mean written examination score than their multimedia counterparts. Another notable finding of the present study was the significant influence of having flight time on aviation students' preparation for the FAA Private Flight Examination. Specifically, aviation students felt that there was a relationship between passing the private pilot exam and having flight time. These findings were parallel to those of Dennis and Harris (1998), Gopher et al. (1994), and Lintern et al. (1990). The findings by these researchers indicated that having flight time improved the performance of students. A reasonable explanation for the current findings might be that having flight time could have assisted the students in their understanding of aviation and allowed them to transfer this knowledge to the written examination.

Moreover, a somewhat surprising finding was the lack of influence of having soloed before taking the Private Pilot Examination on the performance of aviation students on this test. No differences were found in the number of students who pass or fail the FAA Private Pilot Examination. These findings did not correspond with those of Lintern et al. (1990). Lintern and his associates (1990) found a moderate relationship between solo flight and performance. An explanation for prevailing findings might be the criteria used to determine when the students are ready for solo flight. Thus, the criteria used by instructors could have contributed greatly to the performance of students on the written examination.

A final interesting finding of this study was the significant influence of the variables of gender and class attendance on the academic performance of aviation students. Female students did significantly better on the written examination than their male counterparts. In addition, those students who missed fewer days did better on examinations than those who missed more days.

\section{Conclusions}

Based on the findings derived from the results of this empirical study, the following conclusions were reached:

1. In general, regardless of the type of presentation (multimedia or traditional), aviation students had similar written examination scores.

2. It appeared that type of presentation had no influence on the classroom performance scores of aviation scores.

3. Female aviation students outperformed their male peers on the classroom examination.

4. It appeared that aviation students who agreed with having flight experience to prepare them for the Private Flight Examination were significantly more likely to pass.

5. In general, having soloed before taking the FAA Private Flight Examination had no influence on the Private Pilot Written Examination.

6. Aviation students who received traditional presentations and those who received multimedia presentation have similar course satisfaction.

7. It appeared in the introduction to aviation 
class that students who missed fewer dates seem to performed better academically on the classroom examination.

The findings regarding the variable type of presentations and the academic performance of aviation students on the FAA Private Pilot Examination suggest that a combination of instructional strategies, including both multimedia and traditional approaches, is more useful in teaching the skills in the field of aviation. Aviation professionals, especially college educators, should be cognizant of the new techniques that are available to assist their students in acquiring the skills needed to be competent pilots.

The finding concerning the influence of flight experience on the academic performance of students suggests that early hands-on training is an important factor in teaching aviation. Thus, it is important that standard criteria be developed to determine when students are ready to move from the classroom to the pilot's seat.

The findings support Clark's (1994) notion of non-significant difference in instructional technology. His research stated that the instructional method has a greater effect on learning process than delivery method. Thus, it is important that flight instructors and aviation educators stay current with proven teaching methods and procedures. 
Table 1. Frequency Distribution of Participants by Type of Presentation, Gender, and Age

\begin{tabular}{lrc}
\hline \multicolumn{1}{c}{ Characteristic } & Number of students & Percentage of students \\
\hline Presentation type & & \\
\hline Traditional & 16 & 64 \\
Multimedia & 9 & 36 \\
Gender & & \\
\hline Male & 22 & 88 \\
Female & 3 & 12 \\
Age & & \\
\hline 19 or younger & 2 & 8 \\
20-25 & 15 & 60 \\
$26-30$ & 4 & 16 \\
31 or older & 4 & 16 \\
\hline
\end{tabular}

Table 2. t-Test Differences Between the Written Examination Scores of Students Receiving Multimedia Versus Traditional Presentations

\begin{tabular}{lcc}
\hline \multicolumn{1}{c}{ Statistic } & Multimedia Presentation & Traditional Presentation \\
\hline$M$ & 3.11 & 2.25 \\
$S D$ & 1.69 & 1.18 \\
$S E$ & 0.56 & 0.29 \\
\hline Mean difference & 0.86 & \\
$d f$ & 23.00 & \\
$t$ & 1.496 &
\end{tabular}

Table 3. $t$-Test Difference Between the AWS 101 Scores of Students Receiving Multimedia Versus Traditional Presentations

\begin{tabular}{lcc}
\hline \multicolumn{1}{c}{ Statistic } & Multimedia presentation & Traditional presentation \\
\hline$M$ & 3.44 & 3.63 \\
$S D$ & 0.73 & 0.72 \\
$S E$ & 0.24 & 0.18 \\
\hline Mean difference & -0.19 & \\
$d f$ & 23.00 & \\
$t$ & 0.601 & \\
\hline
\end{tabular}

Note.AWS $101=$ Introduction to Aviation course. $p=.554$

Table 4. t-Test Difference Between the AWS 101 Scores of Male and Female Students

\begin{tabular}{lcc}
\hline \multicolumn{1}{c}{ Statistic } & Males & Females \\
\hline$M$ & 3.50 & 4.00 \\
$S D$ & 0.74 & 0.01 \\
$S E$ & 0.16 & 0.01 \\
\hline Mean difference & 0.50 & \\
$d f$ & 23.00 & \\
$t$ & $3.169 * *$ & \\
\hline
\end{tabular}

Note. AWS $101=$ Introduction to Aviation course. $p=.005^{* * ;} * *=$ significant at the .01 level. 
Table 5. Participants' Attitudes on Positive Benefit of Flight Time on Pass Rate

\begin{tabular}{lc|cc|cc|cc}
\hline & & \multicolumn{2}{|c|}{ Agree } & \multicolumn{2}{c|}{ Neutral } & \multicolumn{2}{c}{ Disagree } \\
\hline Status & $n$ & No. & $\%$ & No. & $\%$ & No. & $\%$ \\
\hline Pass & 21 & 16 & 76.2 & 3 & 14.3 & 2 & 9.5 \\
Fail & 4 & 1 & 25.0 & 3 & 75.0 & 0 & 0.0 \\
\hline
\end{tabular}

Table 6. Participants' Attitudes on Positive Benefit of Having Soloed on Pass Rate

\begin{tabular}{lc|cc|cc|cc}
\hline & & \multicolumn{2}{|c|}{ Agree } & \multicolumn{2}{c|}{ Neutral } & \multicolumn{2}{c}{ Disagree } \\
\hline Status & $n$ & No. & $\%$ & No. & $\%$ & No. & $\%$ \\
\hline Pass & 21 & 10 & 47.6 & 9 & 42.9 & 2 & 9.5 \\
Fail & 4 & 1 & 25.0 & 3 & 75.0 & 0 & 0.0 \\
\hline
\end{tabular}

Table 7. Multimedia Versus Traditional Course Satisfaction Results

\begin{tabular}{lc|cc|cc|cc}
\hline & & \multicolumn{2}{|c|}{ Agree } & \multicolumn{2}{c|}{ Neutral } & \multicolumn{2}{c}{ Disagree } \\
\hline Presentation & $n$ & No. & $\%$ & No. & $\%$ & No. & $\%$ \\
\hline Multimedia & 9 & 5 & 55.6 & 2 & 22.2 & 2 & 22.2 \\
Traditional & 16 & 14 & 87.5 & 0 & 0.0 & 2 & 12.5 \\
\hline
\end{tabular}

Table 8. Analysis of Variance Summary of the Regular Basis Scores of Students Receiving Multimedia and Traditional Presentations by Class Attendance

\begin{tabular}{lccccc}
\hline Source of variance & Sum of squares & $d f$ & Mean square & $F$ & $p$ \\
\hline Between groups & 7.531 & 4 & 1.883 & 8.136 & $.000^{*}$ \\
Within groups & 4.629 & 20 & 0.231 & & \\
\hline
\end{tabular}

Note. *significant at the .001 level.

Table 9. Scheffé Matrix of Mean Results of the Scores of Students by Class Attendance

\begin{tabular}{|c|c|c|c|c|c|c|}
\hline \multicolumn{7}{|c|}{ Mean per classes missed } \\
\hline 8 or more & $6-7$ & $4-5$ & $2-3$ & $0-1$ & Observed mean difference & $p$ \\
\hline 1.00 & 1.28 & & & & -0.28 & .843 \\
\hline 1.00 & & 1.60 & & & -0.60 & .322 \\
\hline 1.00 & & & 3.00 & & -2.00 & $.001^{* * *}$ \\
\hline 1.00 & & & & 2.00 & -1.00 & .175 \\
\hline & 1.28 & 1.60 & & & -0.32 & .867 \\
\hline & 1.28 & & 3.00 & & -1.72 & $.006^{* * *}$ \\
\hline & 1.28 & & & 2.00 & -0.72 & $.042^{*}$ \\
\hline & & 1.60 & 3.00 & & -1.40 & .908 \\
\hline & & 1.60 & & 2.00 & -0.40 & .393 \\
\hline
\end{tabular}

Note. $*$ Significant at the .05 level. $* * *$ Significant at the .001 level 
Table 10. Summary of Research Questions

\begin{tabular}{|c|c|c|c|l|}
\hline Research question & Defining statistic & $\boldsymbol{d} \boldsymbol{f}$ & $\boldsymbol{p}$ & \multicolumn{1}{|c|}{ Conclusion } \\
\hline 1 & $t=1.496$ & 23 & .148 & Nonsignificant \\
\hline 2 & $t=0.601$ & 23 & .601 & Nonsignificant \\
\hline 3 & $t=-3.169$ & 23 & .005 & Significant \\
\hline 4 & $X^{2}=6.836$ & 2 & .033 & Significant \\
\hline 5 & $X^{2}=5.855$ & 2 & .061 & Nonsignificant \\
\hline 6 & $f=8.136$ & $4 / 20$ & .000 & Significant \\
\hline
\end{tabular}




\section{REFERENCES}

Carville, S., \& Mitchell, D. (2000). "It’s a bit like Star Trek”: The effectiveness of videoconferencing. Innovations in Education and Training International, 37(1), 42-49.

Clariana, R. B. (2003). The effectiveness of constructed-response and multiple-choice study tasks in computer aided learning. Journal of Educational Computing Research, 28, 395-406.

Dennis, K. A., \& Harris, D. (1998). Computer-based simulation as an adjunct to ab intitio flight training. The International Journal of Aviation Psychology, 8, 261-276.

Dillon, A., \& Gabbard, R. B. (1999, August). Prepare to be shocked: Hypermedia does not improve learning! Paper presented at the annual Americas Conference on Information Systems, Milwaukee, WI.

Gall, M. D., Gall, J. P., \& Borg, W. R. (2003). Educational research: An introduction (7th ed.). Boston: Allyn and Bacon.

Gopher, D., Weil, M., \& Bareket, T. (1994). Transfer of skill from a computer game trainer to flight. Human Factors, 36(3), 387-405.

Harman, C., \& Dorman, M. (1998). Enriching distance teaching and learning of undergraduate mathematics using videoconferencing and audio graphics. Distance Education, 19, 299-309.

Hayes, B. G., \& Robinson, E. H. (2000). Assessing counselor education students' attitudes toward computers and multimedia instruction. Journal of Humanistic Counseling, Education and Development, 38(3), 132-141.

Kearney, M., Treagust, D. F., Yeo, S., \& Zadnick, M. G. (2001). Student and teacher perceptions of the use of multimedia supported predict-observe-explain tasks to probe understanding. Research in Science Education, 31, 589-615.

Lintern, G., Roscoe, S., Koonce, J., \& Segal, L. (1990). Transfer of landing skills in beginning flight training. Human Factors, 32, 319-327.

Lintern, G., Taylor, H. L., Koonce, J. M., Kaiser, R. H., \& Morrison, G. A. (1997). Transfer and quasitransfer of scene detail and visual augmentation in landing training. The International Journal of Aviation Psychology, 7, 149-169.

Marinelli, D., \& Stevens, S. (1998). Synthetic interviews: The art of creating a "Dyad" between humans and machine-based characters. Retrieved October 20, 2007, from http://www.cs.cmu.edu/ حsms/Dyad.pdf

Mbarika, V. W., Sankar, C. S., Raju, P. K., \& Raymond, J. (2001). Importance of learning-driven constructs on perceived skill development when using multimedia instructional materials. The Journal of Educational Technology Systems, 29(1), 67-87.

Morales, C., Cory, C., \& Bozell, D. (2001, May). A comparative efficiency study between a live lecture and a Web-based live-switched multi-camera streaming video distance learning instructional unit. Paper presented at the annual Information Resources Management Association International Conference, Toronto, Ontario, Canada.

Offir, B., Lev, Y., \& Bezalel, R. (2008). Surface and deep learning processes in distance education: Synchronous versus asynchronous systems. Computers and Education. 51, 1172-1183.

Pimentel, M. D. G., Ishiguro, Y., Abowd, G. D., Kerimbaev, B., \& Guzdial, M. (2001). Supporting educational activities through dynamic Web interfaces. Interacting With Computers, 13(3), 353-374. 
VarHagen, C., \& Zumbo, B. (1990). CAI as adjunct to teaching introductory statistics. Journal of Educational Computing Research, 6(1), 29-40.

Williams, B. O., \& Dwyer, F. M. (1996). Interactive effects of mixed-chunk elaboration feedback in facilitating student achievement. International Journal of Instructional Media, 23, 245-255.

Zhang, W. (1995). Multimedia, technology, education and learning. Technological Innovations in Literacy and Social Studies Education. Columbia: The University of Missouri. 